European journal of American studies

\title{
The Gender of the Neuronovel: Joyce Carol Oates and the Double Brain
}

\section{Stephen J. Burn}

\section{OpenEdition}

12 Journals

\section{Electronic version}

URL: https://journals.openedition.org/ejas/17459

DOI: 10.4000/ejas.17459

ISSN: 1991-9336

\section{Publisher}

European Association for American Studies

\section{Electronic reference}

Stephen J. Burn, "The Gender of the Neuronovel: Joyce Carol Oates and the Double Brain", European journal of American studies [Online], 16-4 | 2021, Online since 20 December 2021, connection on 07 July 2022. URL: http://journals.openedition.org/ejas/17459; DOI: https://doi.org/10.4000/ejas. 17459

This text was automatically generated on 7 July 2022.

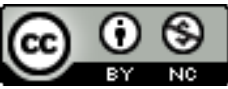

Creative Commons - Attribution-NonCommercial 4.0 International - CC BY-NC 4.0 https://creativecommons.org/licenses/by-nc/4.0/ 


\title{
The Gender of the Neuronovel: Joyce Carol Oates and the Double Brain
}

\author{
Stephen J. Burn
}

Some labels are more compelling than the actual thinking that lies behind them. Sometimes this is because a label's slick sound makes an idea seem more polished than it really is (consider the snappy sounding Brexit). In other cases, a title simply seems impressive because it bears an aural similarity to more austere and rarefied fields (here we might file astrology, bumpology, and craniology as an $A B C$ of -ologies from the pseudosciences). In contemporary literary criticism, the currency of the label neuronovel depends upon a little of both strategies to cover the chasm between term and theoretical justification. The name itself is hard to resist. It flows so smoothly off the tongue-with its pleasingly alliterative $n$ 's and the assonant glide of its paired o'swhile its resemblance to the titles of more rigorous fields (say, neurophilosophy) loans a certain amount of scholarly credit that it typically does not repay. The term initially emerged in its longer form-the neurological novel-and was probably first coined by Oliver Sacks in 1984, when he summarized his book, A Leg to Stand On, as "a sort of neurological novel" (x). ${ }^{1}$ But whatever contemporary eminence the term enjoys is lived out in its abbreviated form, and can be traced to Marco Roth's conservative essay, "The Rise of the Neuronovel" (2009). Unlike Sacks, who was fascinated by the intersection of neuroscience and story, and who would later map this conjunction's genealogy back to A. R. Luria, ${ }^{2}$ Roth's coinage is meant to be derisory. Although he introduces the term with a vague remit-it simply covers novels "wherein the mind becomes the brain"the requirements gradually tighten. He sees such works as only emerging from 1997 onwards, and heralding a much-lamented withdrawal from the novel-"friendly" age of therapy and psychoanalysis, toward an imagined neurology whose putative biological determinism-in the hands of his representative writers Mark Haddon, Rivka Galchen, Jonathan Lethem, and Ian McEwan-denies history and society, marginalizes experimental language, and replaces novelistic meaning with the randomness of evolution's dice roll. 
2 Ten year after Roth's essay, important articles and books have worked to recuperate the term, loosening the label from both his negative assessment and his essay's narrow historical horizons. ${ }^{3}$ Some critics do so by simply omitting any mention of Roth even as their use of the term challenges his axioms. When Andrew Gaedtke discusses contemporary "neuronovels" (183), in the final chapter of Modernism and the Machinery of Madness (2017), his persuasive account of the way Tom McCarthy or Will Self effectively extend modernist "brain mythologies" (190) constructs a long history of the neuronovel that implicitly corrects Roth's claim that the form originates in 1997. Other critics have directly addressed the reductive propositions that underlie Roth's case. Jason Tougaw, for instance, retains the term to describe works by Maud Casey, Thomas Harris, Siri Hustvedt, Ian McEwan, and John Wray in his wide-ranging study of twentyfirst-century literary responses to neuroculture, but does so by carefully distancing his usage from the "extreme claim[s]" of Roth's essay (27). Roth is guilty, Tougaw suggests, of the same reductive thinking that he attributes to the novels he criticizes - "reduc[ing] all science to a singular philosophical point of view or mode of practice" (159)-and missing the irony and the robust critiques embedded in, say, McEwan's treatment of neuroscience. Still others work through detailed individual case studies to unravel the loose stitching that holds together Roth's particular claims that, for instance, innovative neuronovels cannot "do justice" to their "modernist predecessors," or that their adoption of neurological norms "preclude the reader's identification with the characters" (Antolin 48, 51n18).

3 Such efforts represent a key project for readers who are disinterested in policing a border between science and literature that Roth frames in the militaristic terms of ground gained and lost. But, in linking contemporary works to modernist brain mythologies, in challenging Roth's reductive caricature of neuroscience, or in showing the value of neural-influenced innovation, these accounts nuance (with considerable insight) only the first half of this problematic label. This task is important because it is the specifically neuro- element that initially appears contentious, ${ }^{4}$ but in this essay I want to offer a different perspective, and suggest that the seductive power of the prefix neuro- has blinded us to the word's problematic stem: the deceptively routine novel. To date, critics have not asked the relatively simple questions that follow from the conjunction of neuro with, specifically and exclusively, novel, perhaps because those questions seem so simple, or perhaps because the generic classification seems inevitable to the point of invisibility in this novel-dominated age. Yet those questions open onto larger issues raised by the conjunction of neuroscience and literature that include the range and history of such overlaps since the 1960s; the entrance policy that governs which writers are routinely identified as neuronovelists; and the assumptions that underpin the unexamined selection of the novel.

4 What is it, we might start by asking, that makes the novel seem to be the default container for literary explorations of neuroscience? Is it because of the extrinsic example provided by brain researchers, who-like Oliver Sacks in A Leg to Stand Onhave themselves seen the novel as a vehicle to get closer to the intractable problem of how "brain-meat" mediates meaning (Clark xxviii)? To support this position, we might point to neurophilosopher Dan Lloyd's novel, Radiant Cool (2004), which presents itself as "a novel theory of consciousness," or Giulio Tononi's Phi (2012), which reimagines Galileo as a character in a didactic novel "in search of consciousness" (xi). Or is this generic choice driven by the novel's intrinsic qualities, with the designation implying 
some particularly discursive rather than dramatic content that may be ill-suited to either poetry's meditative lyricism or the snapshot qualities of short fiction? Either of these might be the case, but the question remains speculative because for all the appeal of Gillian Beer's "two-way traffic" model of interdisciplinary investigation (5), neither Lloyd's nor Tononi's "novels" are regularly cited in studies of the neuronovel, and no discussions of the neuronovel consider the formal specificity of the novel designation. ${ }^{5}$ This omission is surprising because arguments have, in fact, been made for the ways that the formal qualities of the novel are uniquely suited to engaging with theories of the brain, but these precede the advent of Roth's terminology-belonging instead to the longer tradition of literature and science studies-and, to the best of my knowledge, have never been cited in accounts of the neuronovel. Here we have Tom LeClair's pioneering account of works by writers such as Thomas Pynchon, William Gaddis, and Ursula LeGuin whose sophisticated methods (emphasizing nonlinear interconnections, feedback loops, and self-reference) depend upon the sheer scale of the novel to imitate "the simultaneous and reciprocal processes" of "the collaborative brain" (11). More pithily, John Barth-whose late novels explicitly weave together fiction-making and the brain, ${ }^{6}$ but who never makes it on to the shortlist of neuronovelists-has been hailed by Richard Powers for demonstrating that "the novel can do more than look at the mind; it can look like it" (293).

5 That these questions and reference points have remained beyond the boundaries of work on the neuronovel speaks to the extent to which the form's novelistic qualities have been overlooked, but may also suggest that the subfield can, at times, be guilty of a certain narrowness. Spinoza writes that "every definition is a negation" (qtd. in Hayot 739), and it is the question of what exactly is being negated by the narrowness of the neuronovel's unexamined yet apparently widely accepted genre classification that is worth examining. In the absence of justifications for the novel-specific nature of the neuronovel, we might, then, ask why other literary forms are being negated. If, for Roth, the neuronovel is simply a work "wherein the mind becomes the brain"-a question of content, then, rather than form-why should short fiction, or plays, or poems not merit discussion? After all, it isn't especially difficult to find examples from other genres where the mind has become the brain. A shortlist might start with Clarence Major's "Seine Split"-an example of what Keith Byerman calls Major's identity-problem poems (152) - which recognizably takes its vision of the self, as "divided into two irritated halves" joined by the "corpus collosum" (Configurations 76, sic), from the breakthroughs in split-brain research that were widely reported in the late 1960s and early 70s. This hemispheric pairing becomes the poem's generative model for a sequence of divisions that Major traces from the binaries of quotidian experience (waking/ sleeping, floating/ falling, wholeness/ fragmentation), through mythic twins (Gemini, Castor and Pollux), to the doubleness of the poem's language itself (marked by repetitions and alliterative pairs). Yet, if the issue is neither the richness nor the availability of potential examples, a defender of the neuronovel might, quite reasonably, argue that a more open and expansive term-such as neuroliteratureerases too decisively the generic specificity that neuronovel may not justify but at least implies, requiring us to compare, say, a poem written to a demanding metrical pattern with a play that breaks the fourth wall. But if neuroliterature must be negated, it is much harder to understand why such studies must discuss the novel but exclude short fiction. Without any obvious justification, this untheorized exclusion requires us to curtail the spectrum of literary engagements with neuroscience-omitting an eclectic 
range of short fiction that runs from John Barth's "Stories of Our Lives" (1996) to John Edgar Wideman's "Hunters" (2005) - while it also limits our sense of innovative fiction's horizons. That is, a terminology that cleaves to the novel unwittingly overlooks narratorial experiments with neurology that a writer might explore in a short sketch without committing to a full-scale work. Because of this cluster of problems and exclusions that stem from the prevalence of our current terminology, I propose and favor the term neurofiction as a more precise, flexible, and neutral term to describe fictional works where "the mind becomes the brain." But while I will draw on the wider body of work implied by neurofiction, in order to clearly outline what I think we've missed by using Roth's terminology, I will continue to use neuronovel in this essay to refer to the narrow canon of what Lustig and Peacock more precisely term "syndrome novels."

6 Tightening the terms we employ offers a useful starting point, but it takes us only part of the way toward establishing a clearer and more comprehensive picture of how novelists have engaged with the post-war ascent of the sciences of mind. Questioning the novel in neuronovel surely also entails asking questions about which novelists are routinely gathered under that heading. As Auden wrote of Freud in 1940, the very fact that underwrites the emergence of neuroliterature and neurofields, in general, is that neuroscience is not localized to specific individual figures and projects, but now represents "a whole climate of opinion" that flows freely-at times, indiscriminatelythrough our culture (275): the flurry of popularizations in bookstores, the decontextualized intrusion of the specialist language of serotonin levels or dopamine deficits into everyday speech. If neuroscience seems to be everywhere, and the novelist seeks to record (rather than purify) the language of the tribe, then why is the cast that features in studies of the neuronovel so homogeneously white and male? For some reason, the restrictive focus on the novel in such studies may be a contributing factor, here-as my earlier references to African American authors, Clarence Major and John Edgar Wideman, imply-but, in this essay, I would like to particularly consider the omission of women writers from developing accounts of the neuronovel.

"I didn't want to be thought of as a woman in science, a black woman in science" the neuroscientist protagonist in Yaa Gyasi's Transcendent Kingdom (2020) complains. "I wanted to be thought of as a scientist, full stop" (83). What's at stake in examining the gender asymmetries of many constructions of the neuronovel is not the need for the kind of token representation that Gyasi's Gifty resists-which, in this case, might be documented by a careful reading of a single novel-but that we need to get a much fuller sense of the total range of neurofiction produced by women writers, both across individual careers and as contributions to the field, full stop. Rivka Galchen is often offered as a representative female neuronovelist, but her claims seem, to me, to be fairly minor and localized to a single text, especially compared to, say, Siri Hustvedt, for whom Jason Tougaw has made an exemplary case, documenting not just the significance of her novels, but also their place in a wider career preoccupied with how the brain works (and how it doesn't). To these names might be added Jennifer Egan, whose fiction, from Look at Me (2001) to A Visit from the Goon Squad (2010), insistently yet deftly sets the double brain as the framework for her schematic interrogations of asymmetrical consciousness; Lisa Genova, whose novels variously inhabit characters with brain injuries, working at "redefining normal" (191); Nicole Krauss, not just for her explicit amnesiac-neuronovel, Man Walks into a Room (2002), but also for her experiments with the materiality of the blank page in A History of Love (2005), which 
work to interrupt narration by innovatively rendering both the gaps within and the relatively "slow uptake and limited processing ability" of consciousness (Hayles 10). The sustained engagement with how the brain underwrites the mind across these several careers might be paired with such individual texts as Gyasi's Transcendent Kingdom, Fiona Maazel's A Little More Human (2017), and Lynne Tillman's American Genius (2006) as a way of countering the dominance of the Haddon-Lethem-McEwan-Powers axis.

8 Acknowledging and engaging with this wider range of writers is important not simply because it gives us a stronger sense of the larger cultural shifts that neuroscience has wrought, or for traditional literary critical concerns with bringing breadth and balance to a fairly small, unrepresentative microcanon. It is also important for this field specifically, because questions of race and gender have played such a fraught role in the history of neuroscience. In terms of gender, the desultory history of this relationship can be traced back to no less a figure than Paul Broca, who concluded that "the relatively small size of the female brain... depends in part upon her intellectual inferiority" (qtd. in Gould 136), but-in the context of this essay-the key example comes from lobotomy's short but brutal reign (roughly 1938-1954). In an era when "women were expected to be calm, cooperative, and attentive to domestic affairs" (Tone), lobotomies emerged as a corrective to subversive behavior, with the result that although more men were institutionalized than women, "women were twice as likely to be lobotomized as men" (Corkin 27). The triangulation of gender, science, and power in such medical histories has, inevitably, been registered by writers as various as William Gaddis, Doris Lessing, and Tennessee Williams, and, in turn, tracked by literary scholars. But because such accounts have often crossed generic boundaries-following a subject, rather than a single genre, even when that subject manifests itself in a specific literary style ${ }^{8}$-they rarely fall under the purview of the narrowly conceived neuronovel.

9 The project of moving beyond the limiting boundaries of the neuronovel toward the more expansive horizons of neurofiction-a project that removes the artificial distinction between literary writing about the brain-mind in a short sketch or a longform novel; that moves against the gender asymmetries in the field as it stands; and that challenges the ahistorical notion that such works only emerged in the late 1990s-might, paradoxically, begin its search for a more wide-angle view by considering a single writer: Joyce Carol Oates. ${ }^{9}$ Although Oates is referenced in no study of the neuronovel to date, and rarely features in discussions of literature and science, ${ }^{10}$ she provides a particularly useful starting point for a wider consideration of neurofiction, in part because she professed her fascination with the "relationship between the brain and the 'mind' it somehow generates" as early as 1972 (Oates, Conversations 20), but also because the restless productivity that characterizes her career drives her explorations of that relationship through different genres, linking poems, short fiction, and novels.

10 Oates traces the origin of her interest in neurology back to a suspected medical condition in the 1960s, which necessitated "one or more trips" to a neurologist in Ontario (Afterword 482). The immediate result of these appointments was not a medical diagnosis, but her 1971 novel, Wonderland, a long Lawrentian account of the education and suffering of Jesse Vogel, as he moves from the early trauma of having his entire family killed, in a typically brutal Oates scene, to a career as a famous brain surgeon. 
Wonderland begins with a dedication to "all of us who pursue the phantasmagoria of personality," a pursuit that is complicated in the neuroscientific age by the brain researchers who argue that, beyond language, "personality is an illusion... and we have only the brute matter left-the brain and its electrical impulses" (331). This tension, however, remains at the level of plot in this novel, and never decisively inflects the book's style or architecture. The brain might provide a focal point for Oates's characters' fantasies-whether they involve self-improvement via radical psychosurgery ("if he could have snipped certain neural pathways in his brain bloodlessly, he would have done it" [183]), or imagining a repository for the voices of the dead ("I keep having conversations with him.... He exists in... certain cells of my brain" [410])-but the work the brain does for Oates within the book is circumscribed to whatever editorializing is required within the confines of an individual scene.

Yet if neuroscience initially appears as just another topic consumed by Oates's omnivorous imagination without changing the methods by which that material is transmuted onto the page, Wonderland is nevertheless a generative text in the Oates canon because it introduces a line of works that see the death of the body as an opportunity to encounter "the brute matter" of the physical brain, and to reflect on the intractable mystery of consciousness. In Wonderland such speculations are prompted not just by Jesse's sense that the dead now live within his brain, but also by the seismic impact of the Kennedy assassination, which takes place while Jesse is presenting a conference paper on memory, and which he records as the result of a "bullet in the... brain" (390). Oates extends the topic four years later in "The Brain of Dr. Vicente" (1975). This short sketch presents the story of the "pure brain" of a neuroscientist (27), that has been preserved for eighteen months after his death, and which communicates with the narrator and other specialists "by a chemical and electrical process too complex to explain" (26). So far, so gothic, but what raises the sketch's philosophical stakes is that the story pivots on the brain's refusal to be inserted back into the fleshy, embodied housing of the body: various cadavers are proffered-a handsome twentyyear old, who died (like Kennedy) from a "gunshot wound in the brain" (27); a fifty-nine year old, surgically altered by a perfectionist cosmetic surgeon to resemble the doctor himself-but the pure brain commits to a Cartesian fantasy, rejecting any notion that it might be connected to a body as "Impossible!" (27). The story ends with a careful refutation of this position, by rendering a final glimpse of this pure consciousness as brainmeat: "its three pounds of flesh, its bulges and tubes and delicate silky vessels. We are drawn to it... by a yearning we do not understand" (28).

Oates's next instalment of this investigation comes in her prose poem, "Love Letter, with Static Interference from Einstein's Brain" (1984). The poem's second stanza promises an "asymmetrical... vision" (111), and the poem is-like Major's "Seine Split" a year later-a literary investigation of the asymmetrical processing strengths of the double brain, which (as in Major) provide the logical structure for the sequence of oppositions that Oates traces. As such, "Love Letter" suggests Oates's nascent sense that the brain might provide a frame for structuring a literary work as much as it might also be a subject, but it nevertheless climaxes-like "The Brain of Dr. Vicente"-with a strongly physical encounter with the material brain, in this case Einstein's brain in the hands of the psychohistorian, Julian Jaynes:

(He weighed it in his two hands, he said smiling. Was it uncommonly heavy?-it was not. Was it uncommonly large?-it was not. Did it possess any uncommon features?

-it did not. 'It was a brain like any other,' he said. 'Though it reeked of 
formaldehyde. And turned slightly pale from being so long in its jar beneath the cellar stairs. It had,' he said thoughtfully, 'been dead a long time.') (114) a shape and a significance over the vertiginous patterns of opposites and doubles that typically populate her work. She first glosses how this grid might work in her 1974 story, "I Must Have You," when her narrator describes her obsessive relationship with a man as rendering the two "so close that the halves of our brains could have been paired together, a right-handed brain, a left-handed brain" (170; original emphasis). Later works show her deepening knowledge of Sperry's research-in Childwold (1976), a character reads "of a split-brain patient" whose "left/right selves [are] unaware of each other" $(157)^{11}$-but also add detail to this early sense that characters might be required to represent a single hemisphere, and that the two hemispheres might be classified according to gender. By the time Oates publishes her long story, "All the Good People I've Left Behind" (1979), her characters are offering confident synopses that map the gendered split-brain across their culture:

Our society is a linear one, a rationalist one, it's dominated by what are known as 'left-brain' people-men who have developed the left hemisphere of the brain and who have suppressed the right hemisphere. The left hemisphere... controls rationalist functions. The right hemisphere is the seat of emotions and creativityyou know: spontaneity, warmth, passion. (182, emphasis mine)

Working at the level of character, the schematic dimension implied by such summaries is in line with the decade's popular distillations of split-brain research ${ }^{12}$ with other works of 70s neurofiction, ${ }^{13}$ and can easily be retrospectively applied to classify many of the asymmetrical minds the reader encounters in Oates's earlier work, whether they be cold rationalists or passionate obsessives. But if split-brain research was unique in its cultural penetration, it was also distinct inasmuch as it offered itself as a ready-made 
set of literary styles to narrate those asymmetrical selves. When Don DeLillo described the divergent narration in the two halves of Ratner's Star (1976) as replicating the differences between "left brain, right brain" (87), he may have offered the most explicit example of a writer bending the abstract findings of split-brain research into concrete narrative forms, but he was not alone in doing so. Earlier still, Clarence Major had experimented with narrating purely from the "rationalist functions" of the left brain, emphasizing what Sperry called "analytic, symbolic, computerlike, sequential logic" (31). His short sketch, "An Area in the Cerebral Hemisphere" (1975), therefore preserves sequence, but emphasizes the brutal atomizing work that analysis (from the Greek: a breaking-up) performs on meaning, rendering sentences that would otherwise make sense in broken fragments: "a man in the building across the alley had watched. Her naked movements" (133). Later, Ronald Sukenick experimented with narrating from the right hemisphere in Long Talking Bad Conditions Blues (1979). Replacing the leftbrain's fragments with the right-brain's "holistic and unitary" emphasis (Sperry, "Changing Concepts" 59), Sukenick's novel runs thoughts together in unpunctuated prose that abandons linear sequence in favor of repetitiously weaving backwards and forwards across the same ground: "she always forgot she was getting her period maybe that was because she was a right brain person she knew she was a right brain person because she was left handed" (58). We might call this tendency to transform split-brain theory into narratorial technique split-brain narration. As stream of consciousness is to depth psychology in the 1920s, so split-brain narration describes a method that concisely links cultural context, character psychology, and literary style, as it emerges across the 1970s.

17 As Oates moves away from her direct descriptions of the physical brain in the early 70 s, and toward the direct influence of the split-brain in her later works, so she herself is drawn to experimenting with this technique, though her most explicit example does not arrive until her 2010 short story "Split/Brain," which concentrates on Trudy Gould -emphatically styled as a right-brain thinker-as she travels home from visiting her husband in hospital. Oates's distinct approach in this story can be most clearly seen via contrasts with Major's story. While Major's left-brain sketch unfolds in shards of paragraphs and sentences, Oates's attention to the right-brain's holistic imperative condenses her story into a single, flowing, paragraph. Where Major emphasizes fracture and separation by freely sprinkling periods across his sentences, Oates is relatively sparing with commas, and at times does without periods: "Jeremy please no don't hurt me" (19). Major's clipped prose is replaced by the story's characteristically elastic sentences, which string together several sentences' worth of information into a single, snake-like unit. In a particularly revealing example-which we can read as crystallizing multiple aspects of Oates's experiment with right-brained prose-she writes: "And she kisses his cheek, tells him she will return within the hour; in secret she's childishly relieved to be able to leave the clinic so soon after arriving, this dour dark dimly lighted place, the smells, don't think of the smells, the accumulated smells of decades" (17). As is typical of Oates's approach in this story, her compound sentence presses against the integrity of its own boundaries by beginning with "And," while it further resists segmentation by generating a rhythmic pulse that carries the story relentlessly forward through a mixture of repetition ("the smells... the smells... the accumulated smells"), chains of mostly mono- and disyllabic words, and the alliterative slide of some of her comma-free descriptions ("dour dark dimly lighted place"). That such descriptions are crafted redundancies (dark and dimly lighted?) point to the right- 
brain's preference for the excess of totality over selection, and becomes a recurring trait in a story where the reader is also told that Jeremy is "tall lanky" and has a "hoarse raw" voice (19). A similar combinatory urge is present in the fact that, although the story begins by specifying the single instant of this kiss, other timelines mingle in the sentence: both an anticipated future (her imminent departure and projected return) and recollected past (her arrival that morning, and the longer, medical, stench of institutional history).

If the sustained variety, across four decades, of Oates's fictional engagements with the sciences of mind challenges the assumption that neurofiction is either purely written by white men, or that it is a boutique subject suitable for the rare science-nerd writer (as the stereotype of, say, Richard Powers runs) but of little interest to the mainstream author, then her work across multiple genres also challenges the familiar security of the novel format. Tracking the emergence of split-brain narration, in particular, is only visible if generic horizons are sufficiently wide to permit the kind of jumping between novel and short story that the neuronovel label typically discourages. That said, it is probably only fair to acknowledge that the examples of split-brain narration I've identified have been hidden in plain sight because they advertise the influence of splitbrain studies with either very specific titles (Oates and Major could hardly be more explicit) or with passages whose direct engagement with hemispheric function clearly acts as a metacommentary on the text's own narrative processes (as in DeLillo and Sukenick). Yet it is possible to trace the ramifications of this technique in books that are not explicitly about the double brain, even if we stay within the confines of Oates's oeuvre. The clearest example, in this respect, is offered by her 2016 novel, The Man Without a Shadow.

Moving from the 1960s to the 1990s-that is, from the decade when, in the aftermath of psychosurgery, the term neuroscience was first coined ${ }^{14}$ to the so-called decade of the brain and the era of the MRI-The Man Without a Shadow tells the story of Margot Sharpe's scientific career, as it develops around her studies of the amnesiac patient, Elihu Hoopes. The starting date is significant precisely because it precludes the possibility of hefting the live physical brain in the fashion of "Dr.Vicente" or "Einstein's Brain"; before advances in brain imaging, Oates, reflects, there is "no way into the brain except by... labyrinthine indirections" (196), and split-brain narration provides Oates with that route.

Following Margot's rise, from dutiful graduate student to award-winning seniority, the book is rich with the ephemera of a scientific career-whether scraps from notebooks or professional jealousies-but her story is also, predictably, a "doomed and deranged love" affair (220), as Oates blurs the lines between Margot's scientific dedication and her romantic devotion to her forgetful and vulnerable patient. In its starkest outlines, the book's plot is given away in its opening sentences: "She meets him, she falls in love. He forgets her" (2). But, explored at novel length, and woven carefully around both a specific neurological condition and (as Oates has been at pains to point out) psychological tests "based on real experiments" ("The Terms"), The Man Without a Shadow seems to have little relevance to the split brain, but is Oates's best candidate for a conventional neuronovel. Oates's treatment of amnesia encourages comparison with other works in this subfield-perhaps most explicitly Krauss's Man Walks into a Room (a book that itself looks back to Wonderland) ${ }^{15}$-while Oates also works in the mysterious death of Elihu's cousin as a narrative hook in a manner that follows the pattern of the 
neuronovels Tougaw discusses, by invoking the "conventions of detective fiction" only to dispel them as the book progresses (Tougaw 157).

21 Yet despite these correspondences and overlaps, the more fundamental continuities emerge when we read the book in light of neurofiction: that is, not in line with the neuronovel, but with Oates's long-developing engagement with the brain. While Elihu's neurological condition is not explicitly attributed to the split brain-Margot's mentor, Milton Ferris, hypothesizes (correctly, it turns out) that his amnesia stems from damage to the "hippocampus, located just above the brain stem" $(5,258)^{16}$-that does not mean either that the book's own conception of the brain is, in some totalizing fashion, purely about the hippocampus, or, that Oates has abandoned her tendency to model characters in terms of hemispheric asymmetries. In actual fact, while the book explores the weighty questions that stem from Hoopes's condition-how does identity emerge from memory? How does our understanding of privacy evolve in the age of neuroscience?-layered over the top of these questions is Oates's overarching study of the split minds that themselves study Elihu. This second-order analysis is conducted less in the book's syndrome-related content, and more via Oates's supple narrative technique.

Leah Hager Cohen-one of the few reviewers to discuss the book's narration-describes Oates's style in The Man Without a Shadow as depending upon "the omniscient narrator's penchant for isolating words within a sentence... sequestering them within parenthesis.... The effect is 'distancing'.... As if certain words were so suspect-sordidas to require 'handling' by tweezers or being pinched between fingertips, the way one might hold a (soiled) tissue." Cohen's description, with its faltering syntax and strategic interruptions, is, of course, a playful imitation of Oates's own narration. But while the reviewer's attention to style is welcome, the parody misses its target not just because it is rarely the "suspect" or "sordid" words that are sequestered, but also because attributing the parentheses to an omniscient narrator overlooks the true complexity of the book's polyphonic prose. Viewed not as punctuation designed to order our movement through a sentence, but as graphic symbols in themselves, the curled brackets that mark a parenthesis resemble nothing more than the separated twin hemispheres of a brain examined in transverse section:

$$
\text { ( ) }
$$

23 Read in light of Oates's earlier work, we can see this resemblance as a formal signal that a voice from a different hemisphere is intruding into the text, producing a double voice within a single sentence that stems from the double brain. Because this double voicing occurs across the book, this is the kind of technique that is best illustrated not by a single quote, but by a wider sampling of examples:

Like a morbidly curious scientist he'd recorded his temperature in a notebook, in pencil-(the highest recorded reading was 103.1 degrees F)-before he'd collapsed.

(5)

She wants to think that her scent has become familiar to him. (She has conducted olfactory memory tests with him of her own invention indicating that, yes, E.H. is more likely to remember smells than other sensory cues). (83)

Margot assumes that E.H. was disappointed in her weak reaction to the love poem- 
(if indeed it was a love poem). (212)

In Washington D.C., the NIH (National Institutes of Health)-waves of applause

lapping at her feet, rising swiftly to cover her mouth and engulf her. (342) which interjects in bracketed asides, is clearly unstable and in the process of evolving across the whole book, as these examples suggest, the main text is normally dictated by the right hemisphere telling a story "of emotions... spontaneity... passion" while the parentheses represent the editorial instincts of the left hemisphere's "rationalist functions," qualifying and distancing the initial utterance. As such, the parentheses are typically the opposite of sordid or suspect; they are closer to scientific annotations and corrections. Nor does either voice belong to an omniscient narrator: while rendered in the third-person, they both clearly stem from different sides of Margot's character, literally giving voice to an inner conflict that Oates grounds in neurophysiology. Within the confines of The Man Without a Shadow this polyphonic narration allows Oates to tell two stories at once, simultaneously capturing the shaping influence of Margot's scientific training and her private passionate instincts alongside each other, and, crucially, limning the zones where the two overlap. In a larger sense, however, this device speaks to the evolving trajectory of Oates's neurofiction. First, in a significant development of "Split/Brain"s brief experiment with split-brain narration, where Trudy's thought patterns seem to be entirely dominated by the right brain, the later book shows that Oates has found a technique capable of rendering a more complex inner turmoil. Tracking impulses from both hemispheres, The Man Without a Shadow's parenthesis-rich sentences develop a less caricatured model of split-brain narration, which permits more psychological nuance and perhaps explains why The Man Without a Shadow may have begun "as a short story" ("The Terms") but eventually grew to be considerably longer than "Split/Brain." Second, if this is the Oates work that most clearly resembles the neuronovels of earlier writers, then her ability to inflect her prose to reflect both "rationalist functions" and "passion" spares the reader the unlikely pendulum dialogues, between a "neuroscientist and any 'literary' character," that characterize those millennial neurofictions that effectively restage the twocultures debate (Roxburgh et al. 75).

purpose, here, is not, however, to argue that close attention to a single work might result in that book being added to the shortlist of neuronovels. That The Man Without a Shadow shares similarities with other key works, or that it presents particularly subtle solutions to the subgenre's formal problems, is only incidental. My purpose is, instead, to argue-on the basis of reading Oates's book in dialogue with other works, and in the context of her own oeuvre-that resisting the narrow prerogatives established by the confining label neuronovel provides not simply a fuller sense of the diversity of neurofiction, but also offers a more precise genealogy that charts the way specific narrative techniques have emerged since the 1970s. Nevertheless, it is The Man Without a Shadow's resemblance to the most widely noted neuronovels-especially in terms of their relationship to key source texts-that leads to the final strand of my argument with that term.

As many reviewers noted-and as Oates, herself, acknowledges in the book's concluding note-The Man Without a Shadow's Elihu Hoopes "draws heavily" on Permanent Present Tense (2013), Suzanne Corkin's account of more than four decades spent studying the amnesiac Henry Molaison (Nathans-Kelly). ${ }^{17}$ As the result of a botched psychosurgery, Molaison suffered not only disruption to "long-term memory processes" (Corkin 117), 
he also lost the ability to consolidate new memories, so that any new experiences had a timestamp that "expire[d] within about thirty seconds" (52). "Free from the moorings that keep us anchored in time" (74), Molaison's life-changing loss is neuroscience's gain, and he is credited with having "launched the modern era of memory research" (130), while Corkin describes him as ultimately possessing "the most studied brain in the world" (80). The similarities between Corkin's celebrity patient, H.M., and Oates's E.H., then, are clear, but the connection between novel and source goes beyond bequeathing either a thumbnail character sketch, the loose outlines of a therapeutic situation, or raising a handful of ethical questions about suffering and medical science. Rather than abandoning its nonfictional origins having taken these elements, Oates's novel insistently invokes its source text in order to position her ideal reader (apparently one familiar with both texts) in an uncertain twilight zone between both books. Sometimes she does so via playful echoes of Corkin's title: E.H. is "trapped in a perpetual present" (16), "trapped in the present tense" (233); working with him, Margot has "floated in the present tense" (311). But she does so more consistently by playing a kind of game of shifting overlaps and divergences across the book, where the reader is invited to shuttle between nonfiction and fiction by noting not just the points at which Oates decides to parallel H.M.-their shared interest in crossword puzzles (Corkin xi, Oates 6), their tendency to mistake doctors for old school friends (Corkin 150, Oates 33), and so on-but also those where E.H. is distinct, but at which his distinction is presented in terms that nevertheless evoke his historical ancestor. So, where H.M.'s amnesia stemmed from a failed psychosurgery, which attempted to curtail epileptic seizures, E.H.'s problems would seem entirely separate-they follow from "a particularly virulent strain of herpes simplex encephalitis" caught on a camping trip (4)-were it not for the fact that Oates cannot resist qualifying his misfortune by adding "at least no one had... performed radical psychosurgery on him for some presumably beneficial purpose" (9). What is significant about this game is that its counters are often not the imaginative cornerstones of Oates's fictional world; they are instead the contingent details that add local color to that world. That is, the reader does not need the allusions to Corkin to follow the psychological thriller plot; they are instead for the student of the subject, and they are designed to blur the margins between both works, mixing science and story.

In this respect, The Man Without a Shadow is deeply characteristic of Roth's small sample of neuronovels in ways that reveal the term's internal inconsistencies and ruptures. Like Oates's book, the text of the typical neuronovel is nearly always incomplete in itself. It cannot come to the reader unadorned, but must instead be wrapped in paratextual material-whether dutiful acknowledgment pages or key interviews-that act something like a certificate of authenticity for the novelist's neural explorations. That paratext normally glosses one key source, and serious interpretation becomes contingent upon reading the text, at least partly, in the space between the book and its nonfictional supplement. For The Man Without a Shadow that certificate is provided by Corkin's Permanent Present Tense. For Jonathan Lethem's Motherless Brooklyn (1999) it is Oliver Sacks's “Witty Ticcy Ray” (1970). For Ian McEwan's Saturday (2001) it is Frank Vertosick's When the Air Hits Your Brain (1996). For Richard Powers's The Echo Maker (2006) it is V.S. Ramachandran's Phantoms in the Brain (1998). These are, then, never novels in themselves, at least if that term is meant to identify a book that includes a complete fictional narrative. They are instead satellites, circling some substantial body of scientific research, and the path of their orbit explicitly works to undo the rigidity of 
both our conception of the novel as a bounded object, and of the relationship between fiction and nonfiction. But it is only when we stop thinking in the terms suggested by the title neuronovel that we can get a fuller picture of both the complexity of contemporary fiction about the brain and the novelty of what happens beyond a conventional focus on the novel.

\section{BIBLIOGRAPHY}

Antolin, Pascale. “'His Cramped and Claustrophobic Brain': Confinement and Freedom in John Wray's Lowboy." European Journal of American Studies, vol. 14, no. 2, 2019, https:// journals.openedition.org/ejas/14639. Accessed 20 Jan 2021.

Auden, W.H. Collected Poems. Edited by Edward Mendelson. Vintage-Random, 1976.

Barth, John. On with the Story. Little, 1996.

---. Once Upon a Time: A Floating Opera. Little, 1994.

Beer, Gillian. Darwin's Plots: Evolutionary Narrative in Darwin, George Eliot and Nineteenth-Century Fiction. Cambridge UP, 1983.

Bentley, Nick. "Mind and Brain: The Representation of Trauma in Martin Amis' Yellow Dog and Ian McEwan's Saturday." In Lustig and Peacock, pp. 115-129.

Burn, Stephen J. “Mapping the Syndrome Novel.” In Lustig and Peacock, pp. 35-52.

---. “The Neuronovel.” American Literature in Transition: 2000-2010, edited by Rachel Greenwald Smith, Cambridge UP, pp. 165-177.

---. "Putting the Mind Back into Nature: the American Novel and the Science of Mind." Romantic Presences in Twentieth-Century British and American Literature, edited by Mark Sandy, Ashgate, 2012, pp. 191-207.

Byerman, Keith. The Art and Life of Clarence Major. U of Georgia P, 2012.

Clark, Andy. Supersizing the Mind: Embodiment, Action, and Cognitive Extension. Oxford UP, 2011.

Cohen, Leah Hager. "Love in the Time of Amnesia." Rev. of Man Without a Shadow by Joyce Carol Oates. New York Times Book Review, 12 Feb 2016, https://www.nytimes.com/2016/02/14/books/ review/the-man-without-a-shadow-by-joyce-carol-oates.html. Accessed 10 Dec 2020.

Corkin, Suzanne. Permanent Present Tense: The Unforgettable Life of the Amnesiac Patient, H.M. Basic, 2013.

Daly, Brenda. Lavish Self-Divisions: The Novels of Joyce Carol Oates. U of Mississippi P, 1996.

Dean, Sharon L. “Terror and the Bicameral Mind: Joyce Carol Oates's Use of Julian Jaynes in Her Pseudonymous Fiction." Clues, vol. 15., no. 1, 1994, pp. 41-51.

DeLillo, Don. “An Interview with Don DeLillo." With Tom LeClair. Anything Can Happen, edited by LeClair and Larry McCaffery, U of Illinois P, 1983, pp. 79-90.

Edwards, Betty. Drawing on the Right Side of the Brain. Tarcher, 1979. 
Gaedtke, Andrew. "Cognitive Investigations: The Problems of Qualia and Style in the Contemporary Neuronovel." Novel, vol. 45, no. 2, 2012, pp. 184-201.

---. Modernism and the Machinery of Madness: Psychosis, Technology, and Narrative Worlds. Cambridge UP, 2017.

Genova, Lisa. Left Neglected. Gallery, 2011.

Gould, Steven Jay. The Mismeasure of Man. Penguin, 1996.

Gyasi, Yaa. Transcendent Kingdom. Knopf, 2020.

Hayles, N. Katherine. Unthought: The Power of the Cognitive Nonconscious. U of Chicago P, 2017.

Hayot, Eric. “Against Periodization.” New Literary History, vol. 42, 2011, pp. 739-756.

Johnson, Gary. "Consciousness as Content: Neuronarratives and the Redemption of Fiction." Mosaic, vol. 41, no. 1, 2008, pp. 169-184.

Krauss, Nicole. Man Walks into a Room. Anchor-Random, 2002.

LeClair, Tom. The Art of Excess: Mastery in Contemporary American Fiction. U of Illinois P, 1989.

Major, Clarence. “An Area in the Cerebral Hemisphere.” Statements: New Fiction from the Fiction Collective, Venture, 1975, pp. 133-138.

---. Configurations: New and Selected Poems, 1958-1998. Copper, 1998.

McGilchrist, Iain. The Master and His Emissary: The Divided Brain and the Making of the Western World. Yale UP, 2009.

Medved, Maria, and William Hirst. "Islands of Memory: Autobiographical Remembering in Amnestics." Memory, vol. 14, no. 3, 2006, pp. 276-288.

Nathans-Kelly, Steve. Rev. of The Man Without a Shadow by Joyce Carol Oates. Paste, 19 Jan 2016, https://www.pastemagazine.com/books/joyce-carol-oates/the-man-without-a-shadow-by-joycecarol-oates-revi/. Accessed 11 Dec. 2020.

Oates, Joyce Carol. “All the Good People I've Left Behind.” All the Good People I've Left Behind, Black Sparrow, 1979, pp. 145-227.

---. “The Brain of Dr. Vicente.” The Poisoned Kiss and Other Stories from the Portuguese, Vanguard, 1975.

---. Childwold. Vanguard, 1976.

---. Conversations with Joyce Carol Oates, edited by Lee Milazzo, U of Mississippi P, 1989.

---. “I Must Have You.” The Goddess and Other Women, Vanguard, 1974, pp. 167-181.

---. “Love Letter, with Static Interference from Einstein's Brain.” Iowa Review, vol. 14, no. 3, 1984, pp. 111-114.

---. The Man Without a Shadow. $4^{\text {th }}, 2016$.

---. “The Terms of the Experiment: an Interview with Joyce Carol Oates." Electric Literature, 23 Jan 2016, https://electricliterature.com/the-terms-of-the-experiment-an-interview-with-joycecarol-oates/. 10 Dec 2020.

---. Wonderland [1971]. Introduction by Elaine Showalter, Afterword by Joyce Carol Oates, ModernRandom, 2006.

Ornstein, Robert E. The Psychology of Consciousness. Freeman, 1972. 
Ortega, Francisco, and Fernando Vidal. "Brains in Literature/Literature in the Brain." Poetics Today, vol. 34, no. 3, 2013, pp. 327-360.

Pines, Maya. "We Are Left-Brained or Right-Brained: Two Astonishingly Different Persons Inhabit Our Heads.” New York Times Magazine, 9 Sep 1973, https://www.nytimes.com/1973/09/09/ archives/we-are-leftbrained-or-rightbrained-two-astonishingly-different.html. Accessed 1 Oct 2019.

Powers, Richard. The Echo Maker. Farrar, 2006.

---. “John Barth: An Introduction.” Paris Review, vol. 167, 2003, pp. 292-294.

Reilly, Terry. "Lobotomy, Literature, and Postmodern Discourse from Egas Moniz to Jameson." Landscapes of Memory, edited by Isabel Capeloa Gil, Richard Trewinnard and Maria Laura Pires, U Catolica Portuguesa P, 2004, pp. 443-451.

Rose, Nikolas, and Joelle M. Abi-Rached. Neuro: The New Brain Sciences and the Management of Mind. Princeton UP, 2013.

Roth, Marco. "The Rise of the Neuronovel." $n+1$, Fall 2009, https://www.nplusonemag.com/ issue-8/essays/the-rise-of-the-neuronovel/. Accessed 15 Apr 2010.

Roxburgh, Natalie, Anton Kirchhofer, and Anna Auguscik. "Universal Narrativity and the Anxious Scientist of the Contemporary Neuronovel.” Mosaic, vol. 49, no. 4, 2016, pp. 71-87.

Sacks, Oliver. "Foreword." The Man with a Shattered World by A.R. Luria, Harvard UP, 1987, pp. viixviii.

---. A Leg to Stand On. Touchstone, 1984.

Sperry, Roger. "Changing Concepts of Mind." Man and the Biological Revolution, edited by Robert H. Haynes, Toronto UP, 1976, pp. 49-60.

---. “Left-Brain, Right-Brain.” Saturday Review, vol. 9, August 1975, pp. 30-33.

Springer, Sally P., and Georg Deutsch. Left Brain, Right Brain. Freeman, 1985.

Sukenick, Ronald. Long Talking Bad Conditions Blues. Fiction Collective, 1979.

Tone, Andrea, and Mary Koziol. “(F)ailing Women in Psychiatry: Lessons from a Painful Past.” Canadian Medical Association Journal, 22 May 2018, https://www.cmaj.ca/content/190/20/E624. Accessed 11 Dec 2020.

Tononi, Giulio. Phi: A Voyage from the Brain to the Soul. Pantheon, 2012.

Tougaw, Jason. The Elusive Brain: Literary Experiments in the Age of Neuroscience. Yale UP, 2018.

\section{NOTES}

1. This lineage is preserved in Richard Powers's The Echo Maker, when the Sacks-inspired scientist contemplates writing "a neurological novel" (366).

2. In a foreword to Luria's The Man with a Shattered World, Sacks identified A.R. Luria's pioneering studies of brain injuries in the 1970s as the earliest model for "a neurological "novel"' (xiii).

3. Other critics-including Nick Bentley, Natalie Roxburgh, Anton Kirchhofer, and Anna Auguscik -have been relatively content to use the term uncritically. In one of the most wide-ranging accounts of the form, Francisco Ortega and Fernando Vidal occupy a position somewhere between Roth's critics and supporters, challenging several of his axioms but ultimately agreeing 
that, despite historical precedents, he is "justified" in seeing a distinct form emerging in the late 90s (337).

4. The extent of my considerable sympathy for this task is illustrated by my own small efforts to contribute to it in essays such as "The Neuronovel" (2018).

5. Which is not to say that such studies don't look beyond the novel. Tougaw's voracious study explores graphic fiction and memoir. Gary Johnson's "Consciousness as Content" (2008) precedes Roth's essay, and while it concentrates on novels, Johnson sensibly leaves the question of genre open in favoring the term "neuronarrative" to identify "an emerging subgenre of literature" (171).

6. Once Upon a Time (1994) includes a representative summary of Barth's position: "consciousness itself is the brain's biologically evolved narrativity" (170).

7. The term syndrome novel was coined by Lustig and Peacock to indicate works of literature that betray a fascination with unusual "neurological conditions" (1). Despite the vagaries of Roth's opening polemic in his essay, most of the examples that he ultimately offers-including his later distinction between "hard" and "soft" neuronovels-really hinge on syndrome narration, but his larger case is addressed to the apparently "new reductionism of mind to brain" however it appears in the novel.

8. The key work, here, has been done by Terry Reilly whose conception of the "language of lobotomy" traces "similarities between the language psychometrists use to describe... post lobotomy patients and the language literary theorists... use to characterize constituent features of postmodern discourse" with reference to Williams, Lessing, Allen Ginsberg and Ken Kesey (443).

9. For completeness, the discussion of Oates, here, might be read in light of my earlier essays about both Nicole Krauss and Lynne Tillman in light of neuroscience: see Burn, "Mapping the Syndrome Novel" and "Putting the Mind Back in Nature."

10. While not an essay explicitly about either the neuronovel or literature and science, Sharon $\mathrm{L}$. Dean has read Oates's work in light of Julian Jaynes's extrapolations from split-brain research. More generally, the recurrence of "divided selves" in Oates's work has been read by Brenda Daly in terms of Bakhtin. The reading that follows offers a neuroscientifically based take on Oates's polyphonic narration.

11. Oates may be referring to W.J., a patient whose case was covered in a New York Times feature on split-brain research in 1973. After his corpus callosum was severed in an attempt to control severe epileptic attacks, "it became increasingly difficult to think of W.J. as a single person. His left hand kept doing things that his right hand deplored" (Pines).

12. Such as Robert Ornstein's alignment of the left-brain with the West's empirical rationality and the right-brain with Eastern and esoteric traditions.

13. "the Italians seemed like a right brain race" (Sukenick 59)

14. Nikolas Rose and Joelle M. Abi-Rached begin their study, Neuro, by noting that the term neuroscience was first used in 1962 (5).

15. Krauss seems to allude to Wonderland's dedication when a neurologist questions whether a Tourette's sufferer "truly exists or... [is] just a phantasmagoria of a person" (41).

16. The hippocampus does, however, spread across the two hemispheres.

17. This is not, of course, the only acknowledged or unacknowledged source. The books recurrent references to "islands of memory" ("a beautiful expression," Margot reflects, "she thinks it is Milton Ferris who first employed it" [99]) may echo Corkin's description of "the little islands of remembering that Henry treated us to" (254), but more directly references Maria Medved and William Hirst's “Islands of Memory: Autobiographical Remembering in Amnestics" (2006). 


\section{ABSTRACTS}

For good reasons, most criticism of the term neuronovel has focused on the impact that the eyecatching and fashionable prefix "neuro" has upon the stem, "novel." For less clear reasons, the canon of neuronovels (primarily bequeathed by Marco Roth) has tended to pivot on a homogeneously white-male axis, dominated by Mark Haddon, Jonathan Lethem, Ian McEwan, and Richard Powers. This essay explores what we might learn by enlarging the scale of our analysis and looking beyond the novel, to see how a writer's engagement with neuroculture evolves across novels, poems, and short fictions; and looking beyond the familiar cast of "neuronovelists" to resist its gender asymmetry. Because Joyce Carol Oates's writing about the brain both spans almost half a century, and crosses multiple genres, this essay takes her evolving engagement with split-brain research as a test case to explore how her work highlights the limitations of the label neuronovel. This exploration traces Oates's changing sense of how we might write about consciousness in the age of neuroscience, as her work develops from reflections on the raw material of consciousness in Wonderland (1971) to her sophisticated and innovative use of split-brain narration in The Man Without a Shadow (2016).

\section{INDEX}

Keywords: Joyce Carol Oates; neurofiction; the brain and American literature; gender and neuroscience; split-brain research and fiction

\section{AUTHOR}

\section{STEPHEN J. BURN}

Stephen J. Burn is Professor of Contemporary American Literature at the University of Glasgow. He has written or edited seven books, including American Literature in Transition: 1990-2000 (2018) and Approaches to Teaching the Works of David Foster Wallace (2019). His earlier writing on neurofiction includes “Don DeLillo's Great Jones Street and the Science of Mind" (2009), a special issue of Modern Fiction Studies (2015), and essays on Jonathan Franzen, Nicole Krauss, Richard Powers, Lynne Tillman, and David Foster Wallace. 